\title{
Discharge Body Fluid
}

National Cancer Institute

\section{Source}

National Cancer Institute. Discharge Body Fluid. NCI Thesaurus. Code C142366.

Normal or abnormal secretions expelled from a body location. 